\title{
Manejo de la fibra de vidrio en entorno laboral, potenciales efectos sobre la salud y medidas de control (Revisión)
}

\author{
Handling fiberglass at workplaces, potential health effects and control measures \\ (Review)
}

\author{
Antonello Pietropaoli', Federico Basti ' , Álvaro Veiga-Álvarez² y Jerónimo Maqueda-Blasco ${ }^{3}$ \\ 1. Universidad de L'Aquila. Abruzzo. Italia. \\ 2. Colaborador Medicina y Seguridad del Trabajo. Escuela Nacional de Medicina del Trabajo. Instituto de Salud \\ Carlos III. Madrid. España. \\ 3. Escuela Nacional de Medicina del Trabajo. Instituto de Salud Carlos III. Madrid. España.
}

Recibido: 13-08-15

Aceptado: 17-09-15

\section{Correspondencia}

Jerónimo Maqueda Blasco

Director de la Escuela Nacional de Medicina del Trabajo.

Instituto de Salud Carlos III. Madrid. España.

Correo electrónico: jmaqueda@isciii.es

«Los autores quieren expresar su agradecimiento a Cristina Bojo Canales, documentalista de la Biblioteca Nacional de Ciencias de la Salud del Instituto de Salud Carlos III de Madrid, la asesoría prestada en la elaboración de la estrategia de búsqueda y su contribución en la obtención de la colección bibliográfica.»

Resumen

Resumen: La utilización de fibras de vidrio en sustitución del amianto, además de otras aplicaciones, ha contribuido a disminuir drásticamente la incidencia del mesotelioma y otras asociadas patologías asociadas a su utilización. Sin embargo, estudios recientes apuntan a la posibilidad de que su manipulación no se encuentre exenta de riesgos.

Metodología: Se realiza una revisión bibliográfica de la literatura científica publicada recientemente en las principales bases de datos bibliográficas biomédicas.

Resultados: La principal forma de entrada en el organismo es por vía inhalatoria, por lo que sus principales efectos sobre la salud se producen a nivel de vías respiratorias y su capacidad patogénica depende de su composición química, el tamaño, la biopersistencia y la concentración ambiental. Conclusiones: Existe controversia en la interpretación de resultados de estudios experimentales, aunque muchos autores parecen coincidir en que las fibras 475-glass y la E-glass pueden presentar un mayor riesgo de presentar fibrosis o cáncer pulmonar en animales. La mayoría de estudios en humanos no parece demostrar relación entre exposición con fibrosis pulmonar o la disminución de la capacidad pulmonar, que parecen más relacionadas con el consumo de tabaco. Tampoco existen evidencias claras en cuanto a una posible asociación con determinados cánceres del aparato respiratorio. Estudios recientes sobre efectos citotóxicos y genotóxicos, apuntan a que FMA de diámetro menor de $3 \mathrm{~lm}$ y longitud superior a los $5 \mathrm{~lm}$ pueden inducir alteraciones en las células A549 del epitelio alveolar de los seres humanos con estrés oxidativo y peroxidación de lípidos de membrana, aunque faltan elementos suficientes que permitan confirmar estos hallazgos. En base a las evidencias existentes en la actualidad, la IARC incluye las fibras de vidrio de filamentos continuos y las lanas de vidrio, roca y escoria dentro del grupo 3 como no clasificables respecto a su potencial efecto cancerígeno y las fibras cerámicas refractarias (FCR) dentro del grupo 2B como posibles cancerígenos para los seres humanos. 
Palabras Clave: Fibra de vidrio, fibras cerámicas refractarias, salud, riesgos, laboral, ocupacional, prevención, toxicología, contaminación, ambiental.

Abstract

Abstract: Among other applications, the use of glass fibre instead of asbestos, drastically contributed to reduce not only the mesothelioma incidence but also the other pathologies associated to its use. According to recent studies it could be that the manipulation is not exempt from the risks.

Methodology: a bibliographic scientific literature review was recently published in the main biomedical bibliographic databases.

Results: Since inhaling is the major organism entry route, its main health effects impact on the airwaves. Its pathogenic capacity depends on its chemical composition, the size, the biopersistence and the fibres concentration in the ambient.

Conclusions: Although many authors seem to coincide that 475-glass fibre and E-glass fibre do represent a higher risk of developing fibrosis or lung cancer in animals, there is a controversy when interpreting the results in the experimental study. Most of the human studies reveal do not connect* between the asbestos exposure to the lung fibrosis or to the lung capacity decrease, which are more related to tobacco consumption. A possible association with particular cancers of the respiratory system it is not clearly verified. Although such discovery is just to be confirmed due to the lack of elements, according with recent investigations on cytotoxic and genotoxic effects, the MMFA, with a dimeter less than $3 \mathrm{~mm}$ and more than $5 \mathrm{~mm}$ length, can induce variations in alveolar epithelia cells line, A549, from humans with oxidative stress and membrane lipid peroxidation. Concerning current evidences, the International Agency for Research on Cancer (IARC) includes the continuous filament glass fibres and glass wool, rock wool and slag wool fibres in group 3 unclassifiable as to its carcinogenicity to humans and in group 2 the refractory ceramic fibres (RCF) as possibly carcinogenic to humans.

Med Segur Trab (Internet) 2015; 61 (240) 393-414

Key Words: Glass fibre, refractory ceramic fibres, health, risks, labour, occupational, prevent, toxicity, contamination, ambient. 


\section{INTRODUCCIÓN}

Las fibras de vidrio artificiales, fibras de vidrio sintéticas o fibras minerales artificiales (FMA), conocidas bajo su denominación inglesa Man-Made Mineral Fibres (MMVFs), son compuestos de un material inorgánico fibroso derivados del vidrio de rocas y otros minerales. El uso a escala industrial de las primeras fibras de vidrio minerales comienza finalizada la II Guerra Mundial y en años sucesivos se produce una revolución en el desarrollo de nuevos productos que han ido sustituyendo y desplazando la utilización del asbesto, inicialmente en Estados Unidos y posteriormente en Europa.

La aparición de las fibras de vidrio en el mercado ha supuesto un gran paso para la eliminación o minimización de los efectos sobre la salud derivados de la utilización del amianto, aunque estudios recientes no del todo concluyentes, apuntan a que tanto este tipo de fibras como algunas de origen natural, pueden no ser tan inocuas como inicialmente pudieron ser consideradas. En la actualidad constituyen el mayor subgrupo de fibras inorgánicas utilizadas con fines industriales y comerciales, entre cuyas principales aplicaciones tenemos el aislamiento térmico y acústico, refuerzo de materiales, elaboración de materias primas en la industria textil y electrónica entre otras muchas aplicaciones. En la actualidad se presentan como una de las principales alternativas a la utilización de amianto para fines de aislamiento térmico y acústico. Podríamos decir que junto a algún tipo de nanomateriales fibrilares como las nanofibras, nanotubos y nanocables, se trataría de las fibras manufacturadas más importantes en cuanto a volumen de fabricación y utilización en múltiples y diferentes aplicaciones industriales y domésticas.

Dentro del abanico de las fibras, podemos diferenciar entre fibras naturales y fibras artificiales o manufacturadas, cada una de ellas a su vez pueden ser orgánicas o inorgánicas. Entre las fibras naturales orgánicas tendríamos las de origen animal (como la lana) y las de origen vegetal (como el algodón). Entre las fibras naturales inorgánicas cabría destacar el amianto como más representativo de la gama, debido a la amplitud de aplicaciones que se le dieron hasta que fue catalogado como un producto altamente peligroso para la salud. Entre las fibras orgánicas artificiales podríamos citar los polímeros de celulosa.

En cuanto a la composición y estructura de las FMA, su base molecular es el Óxido de Silicio $\left(\mathrm{SiO}_{2}\right)$, el cual se encuentra de forma polimerizada $\left[\left(\mathrm{SO}_{2}\right) \mathrm{n}\right]$ formado estructuras cristalinas en su presentación natural. Cuando $\mathrm{el} \mathrm{SiO}_{2}$ se somete a temperaturas elevadas $\left(1700-2000{ }^{\circ} \mathrm{C}\right)$ las estructuras cristalinas comienzan a romperse dejando fluir libremente sus compuestos. Si en ese momento en que ha perdido su estructural cristalina el material se somete a un enfriamiento brusco y repentino, se produce una reestructuración de sus componentes moleculares de forma desorganizada, pasando a ser una estructura cristalina a una estructura vidriosa o amorfa. Esta desestructuración del material resultante es lo que le confiere determinadas características específicas como puede ser su elevada resistencia a la tracción, al calor, a la humedad, a productos corrosivos y a agentes biológicos, entre otras. Tras estas fases de calentamiento y el posterior enfriamiento, el resultado es la formación de pequeñas esferas de componente vidrioso que se hacen pasar por una estructura a modo de criba (bushing) donde se produce una segunda refundición de forma que al fluir el líquido a través de los finos orificios, se van generando los filamentos que conforman la fibra de vidrio.

Una de las peculiaridades que presentan esta FMA, es que si durante el proceso de fabricación, cuando se encuentran en fase vidriosa o amorfa, se incorporan determinados compuestos como aluminio, calcio, sodio, etc., el material resultante adquiere características especiales dependiendo de los diferentes componentes que hayan sido añadidos, de forma que podemos obtener FMA con características específicas en cuanto a incrementar su capacidad conductora de luz, de la electricidad, de aislamiento térmico o acústico, su resistencia a la tracción o a los ácidos, a los álcalis o a los microorganismos, entre otras muchas.

El abanico de posibilidades que el óxido de sílice permite en cuanto a sus modificaciones físico-químicas y la diversidad de productos derivados con cualidades 
diferentes, lo convierten junto a los plásticos y nanomateriales, en uno de los compuestos de mayor utilización industrial que podemos encontrar en la actualidad, sustituyendo a otros productos mucho más peligrosos para la salud como puede ser el amianto. No obstante, como cualquier producto químico, su utilización no se encuentra exenta de posibles efectos sobre la salud, sobre los que intervienen tanto la propia composición química de cada material como la estructura física de la misma, en cuanto a longitud y diámetro, que de forma específica o en conjunto determinan las características de durabilidad, biodegradabilidad, biopersistencia y capacidad de reacción biológica de defensa por parte del organismo.

El objetivo del presente trabajo es recopilar información actualizada acerca de los posibles efectos nocivos sobre la salud y las patologías que puedan considerarse relacionadas con la exposición a diferentes FMA, así como describir las principales medidas que se deben adoptar para la prevención de la exposición ambiental e individual en trabajadores que manipulan estos elementos en su actividad laboral.

\section{MATERIAL Y MÉTODO}

Se realiza una revisión de la literatura científica recogida en las principales bases de datos bibliográficas biomédicas como MEDLINE-Pubmed, OSH-UPDATE, CISDOC, IBECS, LILACS, SciELO y Google Académico, para identificar artículos que estudiasen posibles asociaciones entre la exposición ocupacional a la fibra de vidrio con determinadas patologías.

Se confeccionaron diferentes ecuaciones de búsqueda utilizando términos obtenidos del tesauro MeSH, como motor de búsqueda de la base de datos MEDLINE-Pubmed y su correspondiente traducción al castellano, el tesauro DeCS.

Criterios de inclusión:

- Ámbito temático:

- Exposición ocupacional en trabajadores en contacto con la fibra de vidrio en cualquiera de sus variedades.

- Aspectos toxicológicos relacionados con la exposición laboral a la fibra de vidrio.

- Tipo de estudios: Observacionales longitudinales y transversales, analíticos y experimentales.

- Población: Trabajadores relacionados con la producción o manipulación de la fibra de vidrio.

- Periodo de estudio: 2009-2015.

- Idioma: Artículos publicados en español, inglés e italiano.

Criterios de exclusión:

- Artículos de opinión de expertos, cartas al director, protocolos y comunicaciones.

- Estudios ecológicos.

- Estudios realizados sobre población general.

- Estudios que aborden el estudio de las fibras de vidrio desde a vertiente residual o ambiental.

Los términos de búsqueda utilizados fueron: "vidrio", "Industria del Vidrio", "Enfermedades profesionales", con sus correspondientes equivalencias en inglés y combinaciones de términos equivalentes o sinónimos.

La búsqueda final se realizó en junio de 2015 utilizando las siguientes estrategias de búsqueda:

— "Glass"[Mesh] OR "glass"[All Fields] OR "glass industry"[All Fields] AND “occupational diseases”[Mesh]. 
— ("glass"[MeSH Terms] OR "glass"[All Fields]) AND ("toxicology"[MeSH Terms] OR "toxicology"[All Fields]).

- ("Occupational Exposure"[Mesh]) AND "Glass"[Mesh].

— "VIDRIO" or "industria del VIDRIO" [Descriptor de asunto] and "enfermedades OCUPACIONALes" [Descriptor de asunto].

— "VIDRIO" or "industria del VIDRIO" [Descriptor de asunto] and "TOXICOLOGIA" [Descriptor de asunto].

Se completa la información con guías y notas técnicas elaboradas por organismos, instituciones y agencias nacionales e internacionales, así como la normativa europea y en particular, la legislación española relacionada con el tema de estudio.

\section{CLASIFICACIÓN DE LAS FIBRAS DE VIDRIO}

\section{Clasificación en cuanto a su composición química}

El compuesto principal de las fibras de vidrio es el Óxido de Sílice $\left(\mathrm{SiO}_{2}\right)$ que sometido a diferentes procesos de calentamiento y enfriamiento pierde su estructura cristalina transformándose en una estructura vidriosa o amorfa, y dependiendo de los materiales que se incorporen a su estructura molecular, el producto final adquiriere propiedades y utilidades diferentes.

La primera modalidad de fibra de vidrio que apareció en el mercado fue la de clase A, que llevaba incorporado sodio a su estructura molecular lo que potenciaba determinadas características, pero por tratarse de un producto sensible a los productos alcalinos, se trabajó para mejorar alguna de sus cualidades. Con la incorporación de aluminio surgió la fibra de vidrio clase E (electric), que por su elevada capacidad de aislamiento eléctrico se utiliza principalmente para recubrimiento de cables y en industria textil de prendas que requieren este tipo de aislamiento. La fibra de vidrio $S$ (streght) se obtiene a partir de una evolución de vidrio $\mathrm{E}$ y presenta propiedades de alta resistencia mecánica al igual que la fibra de vidrio $\mathrm{R}$ (resistance), desarrollada para satisfacer necesidades específicas en la construcción de material militar y aeroespacial, tratándose de un material con gran eficiencia mecánica en condiciones variables de temperatura y de humedad. La fibra de vidrio D (dielectric) se caracteriza por mantener pérdidas eléctricas muy bajas y se utiliza para elaborar materiales permeables a las ondas electromagnéticas. La fibra de vidrio AR (alcali resistant) se emplea como fibra de refuerzo mezclado con cemento, confiriéndole mayor resistencia y durabilidad. Por último, y entre otros tipos de fibras de vidrio que podemos encontrar en el mercado, la fibra de vidrio C (Chemical) es la fibra utilizada para la producción de lana de vidrio por su resistencia a la acción de productos químicos y a la corrosión (tabla I).

Tabla I. Composición de fibras de vidrio y propiedades a partir de la fibra de vidrio A

\begin{tabular}{cll}
\hline Clase & \multicolumn{1}{c}{ Composición } & \multicolumn{1}{c}{ Características } \\
\hline E & Vidrio alumino-borosilicato & Elevada conductividad eléctrica \\
E-CR & Vidrio alumino-cálcico & $\begin{array}{l}\text { Elevada conductividad eléctrica y alta resistencia a la } \\
\text { corrosión por ácidos }\end{array}$ \\
C & Vidrio sódico-cálcico y óxido de boro & $\begin{array}{l}\text { Alta resistencia a productos químicos y corrosión por } \\
\text { ácidos }\end{array}$ \\
D & Vidrio borosilicato & Elevada constante dieléctrica \\
R & Vidrio aluminosilicato & Alta resistencia mecánica \\
S & Vidrio aluminosilicato y magnesio & Alta resistente a la tracción \\
AR & Composición variada & Alta resistencia a álcalis \\
\hline
\end{tabular}




\section{Clasificación por su estructura}

Las fibras de vidrio presentan diámetro variable según el tipo de fibra y el proceso de fabricación. Su longitud puede variar desde varios $\mathrm{cm}$ hasta menos de un $\mathrm{cm}$ y su densidad oscila entre 2,1 a $2,7 \mathrm{~g} / \mathrm{cm}^{3}$, dependiendo fundamentalmente del proceso de fabricación. Dadas estas características podemos distinguir entre:

Filamentos o fibras de vidrio de filamento continuo, son fibras largas y rectilíneas de diámetros más gruesos que otros tipos de FMA (entre 4 y $25 \mu$ m) y más o menos uniformes. Se producen por fusión y son sometidas posteriormente a sucesivas tracciones hasta conseguir fibras de un diámetro bastante uniforme que se utilizan principalmente en industria textil para fabricación de tejidos, como materiales de aislamiento, de utilización en la industria electrónica y en la construcción. En cuanto a sus riesgos para la salud, los filamentos tienden a fragmentarse originando fibras más cortas, pero debido a su grosor no suelen alcanzar más que las zonas de vías respiratorias más altas y pueden ser eliminados con facilidad.

Lanas, son masas de fibras de longitudes y diámetros variables entrelazadas y desorganizadas. Se producen principalmente por filamentación centrífuga hasta conseguir una estructura de mayas de fibras entrelazadas y desorganizadas. La principal característica de estos tipos de materiales es su gran resistencia a la tracción por lo que son ampliamente utilizados en la formación de estructuras y por su resistencia al calor, también como aislantes térmicos. Algunas de ellas pueden ser respirables y alcanzar porciones más profundas del árbol respiratorio que las fibras de filamento continuo. Dentro de ellas tenemos; Lanas de vidrio, lanas de escoria y lanas de roca.

Fibras cerámicas refractarias (FCR) que se producen a través de procesos químicos sometidos a temperaturas extremadamente elevadas. En su composición suelen incorporar aluminio. Su principal característica es su gran resistencia al calor y a las altas temperaturas por lo que se utilizan como material refractario, aunque también se aprovechan de ellas otras cualidades relacionadas con la característica de baja conductividad eléctrica y acústica que presentan. Son las que parecen presentar mayor riesgo para la salud.

Gráfico 1. Esquema de clasificación de las FMA [International Agency for Research on Cancer (IARC), 2001]

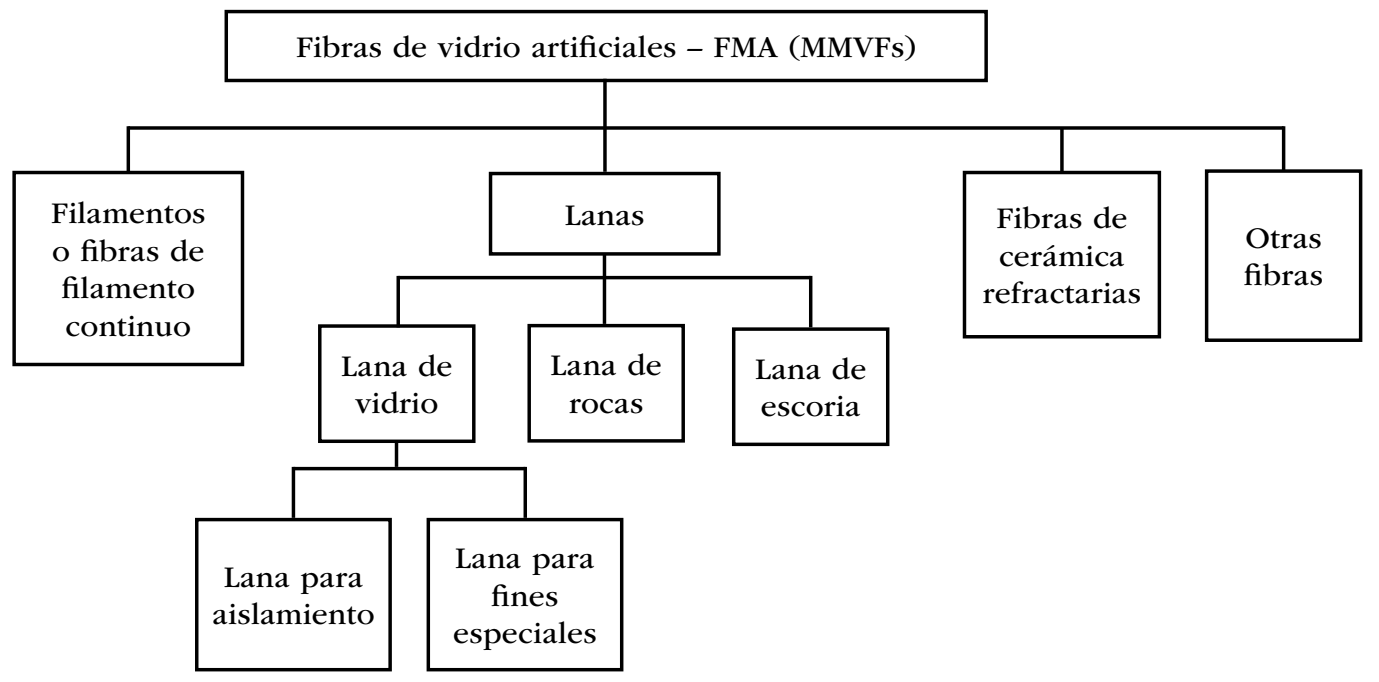




\section{EFECTOS SOBRE LA SALUD}

\section{Exposición}

Los efectos sobre la salud derivados de la exposición a FMA dependen entre otros factores, de la vía de entrada, el nivel de contaminación ambiental, el tiempo de exposición, el tamaño de las partículas, la composición, la capacidad respiratoria del individuo y su ritmo de ventilación pulmonar.

En lo que respecta a la vía de entrada, la forma más habitual suele ser la vía respiratoria. Otras vías de entrada en el organismo como la dérmica suelen ser menos frecuentes, salvo que exista disolución de continuidad de la barrera epitelial. En el caso de producirse contacto dérmico, los efectos suelen ser de tipo irritativo en grado diferente dependiendo de la composición, tamaño de la fibra y de la capacidad de reacción del individuo. La vía digestiva es aún más rara, pues la ingesta de estos productos suele ser accidental o por deglución de mucosidades procedente del árbol respiratorio.

Los niveles de contaminación en aire juegan un papel importantes. Se entiende por transpirabilidad la relación entre concentraciones de las partículas o fibras que se encuentran en el aire y de las partículas que alcanzan los espacios alveolares ${ }^{1}$. El tiempo de exposición a la contaminación atmosférica también juega un papel relevante, no es lo mismo ni se producen los mismos efectos cuando el periodo de inhalación es breve, y por tanto las partículas suelen quedarse retenidas en las vías respiratorias altas, que cuando se produce una exposición mantenida en el tiempo, lo que facilita una penetración de partículas más profunda alcanzando incluso los espacios alveolares. En determinadas circunstancias, como cuando la exposición se produce acompañada de sobrecarga física e hiperventilación, las fibras suelen alcanzar lugares más profundos del árbol respiratorio y cuando se realiza una respiración nasal las partículas suelen quedar atrapadas en las vías respiratorias altas, lo que no ocurre cuando la respiración es por la boca, incrementándose así las posibilidades de producirse depósitos alveolares.

\section{Biopersistencia}

La biopersistencia es un concepto relacionado con la capacidad de permanencia de determinados materiales en el organismo. Depende tanto de la resistencia de las fibras a ser eliminadas como de la capacidad del propio organismo para eliminarlas, por lo que el tamaño, la composición química y la dosis, ejercen un papel importante sobre el equilibrio cinético de la retención/eliminación. Las partículas o fibras de diámetro aerodinámico comprendido entre 1 y $2 \mu \mathrm{m}$ son las que presentan mayor capacidad de depósito y permanencia a nivel alveolar. Cuando aumenta la relación entre la longitud y el diámetro de la fibra, disminuye la capacidad de depósito. Algunos autores refieren que las fibras más peligrosas serían aquellas que se presentan con una longitud superior a 8 $\mu \mathrm{m}$ y diámetro menor de $0,25 \mu \mathrm{m}$ porque tras ser inhaladas pueden penetrar hasta las zonas más profundas del tracto respiratorio ${ }^{2}$. Así, fibras largas y cortas presentan un patrón diferente a la hora de ser eliminadas, las fibras cortas son capturadas por los macrófagos quienes las someten a disolución química/lixiviación, mientras las fibras largas, especialmente aquellas que son más largas de $20 \mu \mathrm{m}$, son eliminadas parcialmente por los macrófagos, por lo que no se logra una eliminación total de las mismas ${ }^{3-5}$.

Cuando la fagocitosis es incompleta se activa un proceso inflamatorio mediante un sistema de liberación en cascada de numerosos mediadores que desencadenan fenómenos de estrés oxidativo inducido mediante especies reactivas del oxígeno y de nitrógeno [Reacting Oxigen Species (ROS) y Reacting Nitrogen Species (RNS)] ocasionando genotoxicidad y proliferación anormal de células, incrementándose la capacidad de liberar radicales libres de peroxidación lipídica de estructuras proteicas celulares y la probabilidad de inducción de daños en el DNA. Por otra parte hay que tener en cuenta que el mecanismo de defensa mediado a través de la fagocitosis puede ser un arma de doble filo, de forma que los macrófagos pueden servir de vehículos de transporte que 
facilitan la diseminación de las partículas y de sus diferentes derivados a distintos puntos sensibles del organismo alejados de la puerta de entrada, especialmente cuando se ha producido una fagocitosis incompleta y persisten las fibras o sus derivados en el interior de estos.

Estudios en animales muestran que la inflamación y la fibrosis pulmonar se encuentran estrechamente relacionadas con la presencia de fibras más biopersistentes. Estos estudios también parecen indicar que la inflamación crónica, la fibrosis y los tumores se encuentran relacionados con una mayor presencia de fibras largas y finas que a la localización de depósitos de fibras cortas e isométricas. Aunque parece estar suficientemente documentado que las fibras de mayor longitud presentan mayor capacidad patogénica y que el diámetro no parece tener tanta influencia ${ }^{1}$, algunos autores consideran insuficiente relacionar solo el grado de patogénesis con el tamaño y composición química de las fibras, por lo que recomiendan completar los estudios mediante test acelulares y celulares tanto in vitro como en vivo para determinar la peligrosidad de las fibras ${ }^{6}$.

\section{Estudios experimentales realizados en los animales}

Desde la irrupción de la FMA en el mercado, se han realizado múltiples estudios en animales para valorar sus potenciales efectos sobre la salud, sobre todo a nivel del aparato respiratorio. La mayoría de estos estudios se han realizados a partir de la exposición de diferentes tipos de fibras en animales de experimentación como ratas y hamsters, utilizando distintas vías de entrada como la intrapleural, intraperitoneal, inhalatoria y la instilación intratraqueal. Existe cierto debate sobre la idoneidad de estos estudios a la hora de valorar posibles efectos sobre población humana porque bastantes autores consideran que muchos de los estudios someten a los animales de experimentación a exposiciones inhalatorias e instilaciones utilizando dosis muy altas y a las que nunca se encontrarían expuestas poblaciones humanas.

Esta polémica se encuentra por otra parte alimentada por el hecho de que diferentes estudios han demostrado que la capacidad de reacción de diferentes especies frente a exposición a FMA es distinta, de forma que estudios realizados en animales para determinar los depósitos de partículas a nivel alveolar, muestran que la respuesta orgánica en ratas y hamsters para la acumulación de fibras a nivel alveolar es diferente a la que se puede encontrar en seres humanos porque la configuración de los sistemas de ventilación son diferentes entre las dos especies.

Algunos autores consideran que la tecnología utilizada en los primeros estudios experimentales utilizaban fibras cortas y se ha comprobado posteriormente que en las ratas no se producen depósitos alveolares cuando el diámetro aerodinámico de las fibras es mayor de 3,5 $\mu \mathrm{m}$ y cuando la relación entre la longitud y el diámetro es mayor de $10 \mu \mathrm{m}$, mientras en los humanos este efecto se produce cuando el diámetro aerodinámico de las fibras se encuentra alrededor de los $5 \mu \mathrm{m}$, siendo por tanto menor la transpirabilidad de fibras inhaladas en las ratas que en los humanos.

Por otra parte, la arquitectura y estructura histológica del pulmón de determinados roedores, como el hamster, parecen mostrar excesiva sensibilidad en pleura mientras presentan cierta dificultad para desarrollar cáncer pulmonar cuando se exponen a fibras biopersistentes ${ }^{7}$.

Algunos autores como Le Bouffant, Muhle y Kamstrup realizaron estudios de inhalación de fibras de lana de vidrio en ratones sin evidenciar efectos cancerígenos ${ }^{8-10}$. Mast y col. realizaron un estudio de revisión sobre los efectos cancerígenos en ratas tras la inhalación de FCR, atribuyendo el exceso de riesgo al haber utilizado procedimientos de inhalación forzada con altas dosis de concentración de fibras, se había producido en las ratas un efecto de sobrecarga pulmonar al que son especialmente sensibles, impidiendo la correcta eliminación de las fibras y facilitándose los procesos de reacción inflamatoria y la aparición de tumores pulmonares ${ }^{11}$. 
Otros autores consideran que al utilizar la vía intrapleural o intraperitoneal como puerta de entrada, no se está utilizando la vía de entrada natural a la que se encuentran expuestos los seres humanos, mientras parece demostrado que cualquier tipo de fibra introducida por vía intapleural o intraperitoneal es capaz de inducir tumores a esos niveles, principalmente mesoteliomas ${ }^{12,13}$.

Estudios más recientes realizados con mejores diseños y métodos de preparación y administración de las fibras, han encontrado un aumento significativo de mesoteliomas en ratas y hamsters cuando se exponían a fibras E-glass. Otros estudios utilizando instilación o implantación quirúrgica intraperitoneal en ratas de altas dosis de fibras de vidrio de aplicaciones especiales como la 475 glass y la E-glass, ambas con un gran poder biopersistente, describieron un elevado potencial carcinógeno o de fibrogénesis pulmonar para estos dos tipos de lanas de vidrio ${ }^{14,16}$, aunque otros autores no han encontrado esta asociación en estudios realizados en hamsters ${ }^{17}$.

En conclusión, mientras algunos autores piensan que la mayoría de los modelos experimentales en animales realizados hasta el momento no son idóneos ni suficientemente sensibles para extrapolar sus resultados a los seres humanos, otros por el contrario, consideran que estudios experimentales orientados a evaluar el potencial efecto carcinogénico o fibrinogénico en el pulmón, pueden ser bastante precisos cuando se encuentran bien diseñados, y en este sentido parece que dos tipos de fibras como la 475 glass y la E-glass, presentan efectos fibrogénicos y carcinogénicos en animales y potencialmente en humanos.

\section{Estudios en humanos}

La mayor parte de evidencias científicas y conclusiones dentro del ámbito epidemiológico se sustentan sobre los resultados de dos grandes estudios de cohortes de seguimiento que se realizaron en Estados Unidos y en Europa, así como resultados obtenidos a partir de posteriores estudios de casos y controles anidados dentro de estas dos cohortes. El estudio de seguimiento de la cohorte de población de Estados Unidos se inició en los años setenta con una población que incluía unos 16.500 trabajadores procedentes de 17 empresas relacionadas con la producción de diferentes fibras de vidrio. Se realizó una primera evaluación de los resultados en 1985 y posteriormente se amplió la cohorte hasta doblar su población para realizar una segunda evaluación a principios de los noventa. El seguimiento de la cohorte europea también se inicia por la misma época, con el seguimiento de unos 25.000 trabajadores de 13 empresas de producción de diferentes fibras de vidrio, realizándose evaluaciones coincidentes más o menos en los mismos años.

\section{Efectos de las fibras de vidrio en estructuras pulmonares}

\subsection{Fibrosis pulmonar y lesiones pleurales}

En poblaciones expuestas a fibras de vidrio y a lanas de roca y de escoria, se realizaron exploraciones radiológicas para medir efectos de fibrosis derivados de dicha exposición. La mayoría de los resultados no mostraron patrones de fibrosis importantes, aunque en algunos de estos estudios no se encontraba bien definido el periodo de exposición, el tipo de fibra ni el control de posibles sesgos asociados al consumo de tabaco o a la exposición a otros agentes como amianto. La mayoría de los estudios no permiten establecer una relación clara entre la exposición a fibras de vidrio y su posible efecto fibrinógeno, aunque tampoco es posible excluir que no exista esta relación en determinados casos concretos de exposición ${ }^{18}$ y podemos encontrar literatura científica que describe algunos casos de patología compatible con fibrosis pulmonar en trabajadores expuestos a determinadas fibras o lanas de vidrio ${ }^{19-22}$.

Resultados análogos se desprenden de estudios efectuados con técnicas radiológicas para determinar la prevalencia del engrosamiento o la visualización de placas pleurales. Algunos estudios refieren presencia de placas de localización pleural en porcentajes 
variables comprendidos entre el $1,3 \%$ y el $5,8 \%$, pero estos hallazgos no difieren mucho de los que se encuentran en la población general urbana, que vienen a ser del orden del 3\%. Además estos porcentajes son muy inferiores a las que se pueden encontrar en poblaciones que se encontraron expuestas a amianto y en las que se describían porcentajes del $10 \%{ }^{23}$.

Rossiter en el 1994 estudian una cohorte de población europea, en la que encontraron que 15 sujetos presentaron anomalías pleurales, lo que suponía el 2,8\% de la población seguida. De los 15 trabajadores afectados, 8 de ellos (52\%) habían trabajado en una fábrica con riesgo de exposición al polvo y de ellos, el 4,5\% habían estado expuestos a amianto y el $7 \%$ había estado sometido a una exposición a otras fibras minerales ${ }^{24}$.

En el 1995 Trethowan incrementó la población de estudio de Rossiter con 91 mujeres en las que se había encontrado anomalías pleurales análogas en el 2,7\%, pero algunos de los casos se habían producido coincidiendo con alguna exposición previa a amianto $u$ otro tipo de factores de riesgo ${ }^{25}$.

Lemasters estudió una población de 847 trabajadores estadounidenses de ambos sexos, que eran empleados de industrias involucradas en la producción o utilización de fibras de vidrio, encontrando una prevalencia de alteraciones pleurales del $2,7 \%$ del total de la cohorte estudiada y del $3,4 \%$ en aquellos trabajadores que se encontraban directamente relacionados con la cadena de producción. De estos, 21 (2,45\%) de los casos presentaban placas pleurales y 2 casos de engrosamientos pleurales ${ }^{26}$.

Lockey en el 1996 obtuvo resultados similares mediante un estudio de casos y controles sobre 652 trabajadores expuestos y no expuestos, describiendo un porcentaje de $3,1 \%$ de anomalías en sujetos que trabajaban en los procesos de producción (19 casos con placas pleurales y 1 caso de engrosamiento pleural) ${ }^{27}$.

Muchos de los estudios encontraron relación entre algunas anomalías pleurales y la edad, el índice de masa corporal, el periodo de exposición y periodo de latencia desde la primera exposición. En particular, Lockey y cols. encontraron una $\mathrm{OR}=9,5$ estadísticamente significativa para expuestos con más de 20 años de latencia desde la primera exposición, $\mathrm{OR}=22,3$, también significativa para la exposición superiores a 20 años en los trabajadores de la cadena de producción y una $\mathrm{OR}=24,2$ significativa para exposición en la categoría de los expuestos a elevadas concentraciones ambientales ( $>135$ fibras $-\mathrm{cm}^{3} / \mathrm{mes}$ ). En un estudio posterior, este mismo autor confirma la existencia de una relación entre la presencia de placas pleurales y el periodo de latencia desde la primera exposición, el tiempo de exposición y exposición acumulada en $20 \operatorname{casos}^{27}$.

A finales de 2002 Lockey realiza un estudio sobre los 625 trabajadores comparando los resultados con los de 338 ex-expuestos a fibras de vidrio, encontrando una relación significativa entre progresiones de anomalías pleurales y exposición cumulativa en ambientes con concentraciones superiores a las 135 fibras-cm $3 / \mathrm{mes}^{28}$.

Se ha descrito también alguna relación entre las alteraciones intersticiales y el tiempo de exposiciones en los trabajadores que desarrollaban sus actividades laborales en la cadena de producción con una exposición cumulativa a fibras de cerámica refractaria (FCR), lo que sugiere que pudiera existir una relación entre las anomalías pleurales y la exposición a FCR. En cuanto a esta relación entre alteraciones intersticiales y exposición a FCR, se encuentran diferencias entre los resultados de los estudios efectuados en Europa y en Estados Unidos, lo que podría ser explicado porque la introducción de FCR ha sido más reciente en Europa que en Estados Unidos y podría haber menor tiempo de exposición en la población europea que en estadounidense.

También se evaluó la exposición a FCR en relación a las opacidades parenquimatosas pulmonares en la cohorte Europea y en la de EEUU. En las cohortes americanas Lemasters y Lokey identificaron un número de imágenes radiológicas caracterizadas por la presencia de opacidades intraparenquimatosas en personas que habían estado expuestas a FCR, pero en el número de observaciones no presentaba el tamaño suficiente para realizar un análisis estadístico ${ }^{26,27}$. En las cohortes Europeas se encontró un $7 \%$ de pequeñas 
opacidades parenquimatosas de categoría 1/0 o almo más correspondientes a la clasificación de la Organización Internacional del Trabajo (OIT/ILO). En estudios realizados da Cowie en Europa, también se encontraron pequeñas opacidades de difusión de categoría 1/0 o más, asociadas a la exposición a FCR ${ }^{29}$.

Aunque estos estudios no son concluyentes porque otros factores como la edad, el consumo de tabaco o exposiciones precedentes a amianto, podrían estar influyendo sobre los resultados finales, parecen apuntar hacia la posibilidad de que las FCR puedan tener un papel en la aparición de opacidades intraparenquimatosas pulmonares.

\subsection{Alteración de las pruebas de función pulmonar}

Varios autores como Lockey, Lemaster, Trethowan y Burge, que realizaron estudios sobre la población americana y europeas, coinciden en que una exposición acumulada a FCR se asocia con una reducción de la función pulmonar en fumadores y exfumadores ${ }^{25,28.30,31}$.

En el 1995 Trethowan ${ }^{25}$ completó los estudios previos con pruebas espirométricas realizadas a 600 trabajadores expuestos a FCR controlando por edad, consumo de tabaco y exposición anterior a otros factores de riesgo. Encontró una relación estadísticamente significativa entre la reducción del FEV1 y del FEV 25-75 detectada en poblaciones de fumadores y exfumadores con exposiciones acumuladas a FCR. En los no fumadores los resultados del análisis de regresión mostraban también asociaciones positivas entre estas dos variables pero no estadísticamente significativas.

Burge también estudió el papel que podía jugar la exposición a FCR respecto a otro tipo de exposiciones a polvo inhalable comparando los resultados de pruebas espirométricas (FEV 1 y FEF 25-75), encontrando también una asociación estadísticamente significativa entre exposición cumulada a FCR y la reducción de FEV1 y FEF 25-75 en los fumadores y a FEV1 en exfumadores ${ }^{31}$.

Lemasters realizó un estudio en 735 trabajadores procedentes de 5 tipos de industrias diferentes de Estados Unidos, encontrando una reducción significativa de FEV1 y FVC en aquellos trabajadores que habían estado trabajando más de 10 años en la cadena de producción, aunque las anormalidades espirométricas se evidenciaron solo en los grupos de fumadores y exfumadores, mientras no se encontraron diferencias estadísticamente significativas para el grupo de no fumadores. Este autor también encontró un déficit de funcionalidad respiratoria estadísticamente significativa en las mujeres que no fumaban ${ }^{30}$.

Cowie, describió resultados similares a los anteriores, encontrando una fuerte relación entre la disminución del FEV1 y del FVC en las poblaciones fumadoras expuestas a FCR ${ }^{29}$.

Lockey y col. estudiaron las modificaciones espirométricas que se producían durante el seguimiento de una población estudiada durante el periodo 1980-1990, controlando por edad, sexo, hábito de fumar, el tiempo y la dosis de exposición sin hallazgos significativos respecto a modificaciones de FCV y FEF1 tras la exposición acumulada a FCR. Estos autores continuaron el estudio ampliando el periodo hasta 1994 encontrando resultados similares ${ }^{28}$. McKay y col. tampoco lograron evidenciar disminución de la función pulmonar después de estudiar a 1.396 trabajadores y extrabajadores expuestos a FCR durante un periodo de 17 años $^{32}$.

\subsection{Síntomas irritativos pulmonares}

Aunque en la literatura científica no podemos encontrar muchos estudios centrados en los efectos irritativos originados por exposiciones a FMA sobre piel y mucosas, Lokely, Thriene y Bergamaschi, describieron estos efectos asociados al contacto con FMA, principalmente cuando el diámetro de las fibras era mayor de $4 \mu \mathrm{m}$. También se han descrito alergias cutáneas por contacto con diferentes aditivos que se encontraban presentes en determinadas FMA y que habían sido añadidos durante el proceso de fabricación ${ }^{33-35}$. 
Thestrup y col. realizaron un estudio en 66 personas expuestas al síndrome de edificio enfermo, encontrando que un $62 \%$ de la población estudiada mostraba positividad a los test de alergia a diferentes materiales de aislamiento utilizados ${ }^{36}$.

Estudios realizados en poblaciones americanas y europeas encontraron que trabajadores expuestos a FCR presentaban un aumento significativo de irritaciones oculares, congestión nasal y tos seca en aquellas poblaciones que se encontraban sometidas a concentraciones ambientales entre 0,2 y $0,6 \mathrm{ff} / \mathrm{cm}^{3}$ en relación a los trabajadores cuya exposición ambiental era menor de $0,2 \mathrm{ff} / \mathrm{cm}^{3}$. También se observó un aumento de disnea de grado II, irritación ocular y cutánea, sin congestión nasal, en los trabajadores expuestos a concentraciones $>0,6 \mathrm{ff} / \mathrm{cm}^{3}$ respecto a aquellos cuya exposición se encontraba entre 0,2 y $0,6 \mathrm{ff} / \mathrm{cm}^{3}$ en mediciones ambientales ${ }^{25-31}$.

\subsection{Estudios sobre mortalidad por cáncer de pulmón}

\subsubsection{Fibras de vidrio de filamento continuo y cáncer de pulmón}

Aunque los resultados de Shannon sobre el estudio de una cohorte canadiense durante el periodo 1980-1990, encontraron un incremento de la mortalidad por cáncer de pulmonar en los trabajadores expuestos a lana de vidrio, sin relación con el tiempo de exposición ni con el periodo de latencia desde la primera exposición ${ }^{37}$, la mayoría de los estudios realizados sobre las dos grandes cohortes de seguimiento de poblaciones de Estados Unidos y de Europa, no mostraron aumentos de mortalidad por cáncer de pulmón u otra localización del aparato respiratorio.

Estudios realizados por Marsh ampliando el periodo de estudio inicial de estas dos grandes cohortes, mostraron un incremento moderado de la mortalidad por cáncer de pulmón en los expuestos a lana de vidrio de la cohorte de Estados Unidos aunque sin diferencias significativas cuando se realizaba una estandarización de las tasas de mortalidad tomando como base la población local (SMR: 1,12). Tampoco encontraron relación con el tiempo de exposición ni con el periodo de latencia, incluso pudieron observar que los trabajadores con un tiempo de exposición menor presentaban mayor riesgo de padecer un cáncer de pulmón que los que se habían encontrado expuestos a periodos más prolongados ${ }^{38}$. Este mismo autor realizó en 2001 un estudio de casos y controles sobre una población americana perteneciente a diez industrias relacionadas con la producción de FMA para estudiar el riesgo de desarrollar un cáncer de pulmón, sin que se obtuvieran incrementos significativos de este tipo de tumores en la población expuesta. Tampoco se encontró asociación con el tiempo de exposición, la exposición acumulada, el periodo de latencia tomando como inicio el primer empleo ni entre los diferentes tipos de sistema de producción ${ }^{39}$.

Stone y col. realizaron un estudio de casos y controles sobre una población de trabajadores pertenecientes a la cohorte americana para analizar la relación entre la exposición a fibra de vidrio y el cáncer de pulmón, no encontrando relación ni con la duración de la exposición, ni con la intensidad ni con el tiempo de latencia, encontrando el consumo de tabaco el factor de riesgo más asociado al riesgo de aparición de cáncer pulmonar $^{40}$.

En las cohortes europeas de los trabajadores de la producción de FMA tampoco se encontraron incrementos significativos de la tasa de mortalidad por cáncer de pulmonar. Gardner realizó un estudio de casos y controles tomando como base la cohorte de población europea y no encontró un mayor riesgo de mortalidad estadísticamente significativo para el cáncer de pulmón tras las exposiciones ${ }^{41}$. Los estudios de revisión realizados por Boffetta en el 1999 sobre más de 2.600 trabajadores de tres empresas diferentes no evidencian tampoco relación entre cáncer pulmonar y la exposición a fibra de vidrio, ni asociaciones con el tiempo de exposición, periodo de latencia o la modalidad de producción $^{42}$. 


\subsubsection{Lanas de roca y lanas de escoria y cáncer de pulmón}

Simonato y col. realizaron un estudio basado en la cohorte europea sobre 37 trabajadores que habían estado expuestos a inhalación de estas lanas de vidrio durante periodos anteriores a que se estableciesen medidas preventivas de protección inhalatoria. Aunque encontraron un incremento de cáncer de pulmón en los trabajadores expuestos, pero el incremento, con un $70 \%$ de la tasa de prevalencia de tumores pulmonares coincidía con la población de trabajadores de 2 fábricas en las que se habían encontrado expuestos al amianto, por lo que sin poder excluir que la exposición a lana de roca y lana de escoria puedan tener algún papel en el desarrollo de este tipo de tumores, tampoco se podía concluir de los resultados del estudio que fueran la causa del mismo ${ }^{43}$.

Kjaerheim y col. realizaron un estudio de casos y controles, controlando diferentes factores de riesgo incluido el consumo de tabaco actual o anterior, no encontrando asociación significativa entre las exposiciones y el incremento de riesgo para cáncer de pulmón o mesotelioma ${ }^{44}$.

Metaanálisis llevados a cabo por Berrigan y col. (2002) y Lipwort y col. (2009), encontraron un discreto aumento del riesgo para cáncer de pulmón en trabajadores expuestos a lanas de escoria y cáncer de pulmón, aunque en ambos estudios concluyeron que este ligero incremento podía encontrarse más ligado al consumo de tabaco o a exposiciones al amianto de forma independiente o simultánea ${ }^{45,46}$.

En resumen, la mayoría de autores consideran que no existe evidencia suficiente para atribuir una asociación causal entre exposición a lanas de vidrio y lanas de roca y el cáncer de pulmón ni para el mesotelioma ${ }^{47}$.

\subsubsection{Fibras Cerámicas Refractarias (FCR) y cáncer de pulmón}

Lockey y col. publicaron en 1993 los resultado de un estudio realizado entre 1950 y 1988 sobre 684 trabajadores varones que habían desarrollado su actividad laboral en industrias de producción de FCR con al menos un año de antigüedad en el puesto de trabajo, analizando la mortalidad por todas las causas, para todos los tipos de tumores, para tumores concretos como cáncer pulmonar, urológico y digestivo, así como para otro tipo de patologías no tumorales como neumoconiosis y enfermedades infecciosas respiratorias. No observaron ningún aumento significativo de mortalidad en la totalidad de la cohorte, estratificada por caucásicos y no caucásicos; sin embargo, había un aumento significativo de mortalidad para neumoconiosis e infecciones respiratorias no cancerosas entre los trabajadores de raza blanca con un periodo de latencia respecto a la primera exposición de más de 30 años, un aumento significativo de mortalidad por cánceres del aparato digestivo y del peritoneo para los trabajadores no caucásicos y un aumento significativo de cáncer del tracto urinario para trabajadores con un periodo de latencia comprendido entre 15 y 20 años desde la primera exposición, pero el escaso número de casos no permitía establecer conclusiones fiables a partir de los resultados del estudio ${ }^{28}$.

Lemasters y col. estudiaron durante el periodo comprendido entre 1952 y 2000 , una cohorte de 942 trabajadores que desarrollaban su actividad laboral expuestos a la FCR. Los resultados no encontraron incremento de riesgo de mortalidad por todas las causas, ni para todos los cánceres ni para patologías tumorales respiratorias, encontrando una posible relación de exposición a FRC con el cáncer del tracto urinario ${ }^{48}$.

Walker estudió la misma cohorte de trabajadores de industria productora de FCR realizando un análisis de riesgos relacionando la mortalidad por tumor pulmonar y mesotelioma comparándola con la mortalidad esperada, considerando que la exposición a FCR pudiera ser potencialmente carcinógena y comparable al riesgo de exposición al amianto. Los resultados mostraron que la cohorte de los trabajadores expuestos a FCR presentaba una mortalidad por cáncer de pulmón significativamente menor de lo que cabría esperar si el FCR tuviera el mismo potencial patogénico que la amosita o la crocidolita $^{49}$. 
Los resultados obtenidos en la mayoría de estudios, incluyendo los dos principales estudios de las dos grandes cohortes de expuestos a fibras de vidrio realizados en los Estados Unidos y en Europa, han llevado a la IARC a concluir que no existen evidencias suficientes sobre la capacidad carcinogénica de las fibras de vidrio para los seres humanos ${ }^{50}$.

\section{Citogenotoxicidad y el estrés oxidativo}

Venerardo y col. estudiaron la capacidad citotóxica, genotóxica y de estrés oxidativo que podían inducir las fibras de vidrio sobre las células del epitelio alveolar A549 en los humanos. Mediante dosificación FMA se midieron los efectos de citotoxicidad expresados en proporción de células viables en comparación con cultivos de control no tratados (100\%). En cuanto al tipo de fibras de vidrio utilizadas, el 97\% tenían un diámetro menor de $3 \mathrm{~lm}$ y el 93\% una longitud superior a los $5 \mathrm{~lm}$. Los resultados mostraron que a dosis bajas la exposición a fibra en los tejidos incubados se producían cambios sobre la vitalidad celular. Exposiciones a dosis más altas reducían considerablemente la capacidad de metabolizar las sales de tetrazolio, observándose que las fibras de vidrio compuestas de $\mathrm{SiO}_{2}$ y de $\mathrm{B}_{2} \mathrm{O}_{3}$ producían un marcado efecto citotóxico/genotóxico, dosis-dependiente, estrechamente relacionado con el nivel de estrés oxidativo. Todas las concentraciones, desde $5 \mathrm{lg} / \mathrm{ml}$ hasta $100 \mathrm{lg} / \mathrm{ml}$, inducían una reducción de la vitalidad celular que se mostraba dosis dependiente con un aumento de la porcentaje de DNA de transferencia (T-DNA), y el "tile moment" (TMOM), con un claro daño directo sobre el DNA, de forma que al cabo de 72 horas, el porcentaje de T-DNA y TMOM en las células expuestas se incrementaba de forma significativa en comparación con los de las células control ( $\mathrm{p}<$ 0,001). Por otra parte, se encontraba un marcado efecto dosis-repuesta de forma que el daño en el DNA aumentaba conforme se incrementaba la concentración de fibras, observándose un incremento en la síntesis de inducible Nitric Oxide Synthase (iNOS), visibles muestras de síndrome oxidativo en las células A549 expuestas y un incremento de la [Reacting Oxigen Species (ROS) y Reacting Nitrogen Species (RNS), aumento del óxido de nitrógeno (NO) y disminución de antioxidantes, como el glutatión, involucrados en la eliminación de radicales libres de oxígeno, lo que parece ser el mecanismo subyacente a la toxicidad de fibra de vidrio cuyos efectos probablemente conducen a un aumento de la peroxidación de lípidos de la membrana.

Resultados similares fueron descritos por Cavallo y col. mostrando igualmente un aumento del daño dosis-dependiente con incremento de la T-DNA, TMOM que a dosis de exposición bajas causaban ligeros efectos genotóxicos y citotóxicos y a dosis más altas una ligera reducción de las microvellosidades de la membrana cuando se exponían las células a dosis, de forma que los resultados de estos estudio indican que las fibras de vidrio pudieran ser considerados como potencialmente implicados en el inicio de la carcinogénesis $^{51}$.

En la tabla II se presentan, a modo de resumen y de forma sintética, los principales efectos observados sobre animales de experimentación y en seres humanos.

Tabla II. Evidencias más relevantes en los seres humanos demostradas con estudios experimentales con animal

\begin{tabular}{llll}
\hline & $\begin{array}{c}\text { FIBRAS DE VIDRIO DE } \\
\text { FILAMENTO CONTINUO }\end{array}$ & $\begin{array}{c}\text { LANA DE ROCA } \\
\text { Y ESCORIAS }\end{array}$ & $\begin{array}{c}\text { FIBRAS CERÁMICAS } \\
\text { REFRACTARIAS }\end{array}$ \\
\hline $\begin{array}{l}\text { Neoplasias pulmonar y } \\
\text { mesoteliomas }\end{array}$ & $\begin{array}{l}\text { Evidencia insuficiente en } \\
\text { los seres humanos, limitada } \\
\text { a los animales (1) (3) }\end{array}$ & $\begin{array}{l}\text { Evidencia insuficiente } \\
\text { en los seres humanos, } \\
\text { limitada a los animales (1) limitada a los animales (2) }\end{array}$ & $\begin{array}{l}\text { Evidencia insuficiente } \\
\text { en los seres humanos, }\end{array}$ \\
Placas pleurales & No & No & Sí \\
Patología intersticial & No & No & $\begin{array}{l}\text { Comprobado en } \\
\text { animales. } \\
\text { Posibles efectos en seres } \\
\text { humanos. }\end{array}$
\end{tabular}




\begin{tabular}{|c|c|c|c|}
\hline & $\begin{array}{l}\text { FIBRAS DE VIDRIO DE } \\
\text { FILAMENTO CONTINUO }\end{array}$ & $\begin{array}{l}\text { LANA DE ROCA } \\
\text { Y ESCORIAS }\end{array}$ & $\begin{array}{l}\text { FIBRAS CERÁMICAS } \\
\text { REFRACTARIAS }\end{array}$ \\
\hline Problemas respiratorios & Sí & Sí & Sí \\
\hline $\begin{array}{l}\text { Alteración en la } \\
\text { función respiratoria }\end{array}$ & Sí/No (4) & Sí/No (4) & Sí \\
\hline $\begin{array}{l}\text { Irritaciones de la piel y } \\
\text { mucosas }\end{array}$ & $\begin{array}{l}\text { Sensibilización inducida por } \\
\text { fibras de longitud }>4 \mu \mathrm{m} \text { y } \\
\text { por aditivos }\end{array}$ & $\begin{array}{l}\text { Sensibilización inducida por } \\
\text { fibras de longitud }<4 \mu \mathrm{m} \\
\text { y por aditivos }\end{array}$ & Sí \\
\hline
\end{tabular}

(1) Clasificación IARC 2002: grupo 3. Clasificación carcinogénica CE: categoría 3 (Directiva 97/69/CE).

(2) Clasificación IARC 2002: grupo 2B. Clasificación carcinogénica CE: categoría 2 (Directiva 97/69/CE).

(3) Excepción para las fibras de vidrio para el uso especial E-glass y las fibras " 475 glass" para los cuales la IARC evalúa una suficiente evidencia de carcinogénica en los experimentos con animales, por lo que se clasifican en el grupo 2B.

(4) Resultados controvertidos

\section{RECOMENDACIONES DE ORGANISMOS INTERNACIONALES Y MARCO LEGAL}

A partir de 2002 y en base a los estudios realizados, la IARC consideró que no existían evidencias suficientes de carcinogenicidad en humanos para fibras de vidrio de filamento continuo, lanas minerales y FCR, aunque las limitaciones que presentaban los estudios epidemiológicos, principalmente relacionados con la medición de las dosis, periodos de latencia y factores de confusión cono tabaquismo y exposición a otros tipos de fibras como amianto, recomendaban cierta prudencia a la hora de interpretar los resultados.

Se considera que no existe evidencia suficiente para determinar que la exposición a fibras de vidrio de filamento continuo, lanas de vidrio, de roca y de escoria están relacionadas con el cáncer de pulmón, por lo que se las clasifica dentro del grupo 3.

En cuanto al potencial carcinogénico de determinadas fibras como E-glass, 474-glass y las FCR, se considera que pueden jugar algún papel carcinógeno en animales de experimentación, aunque no se encuentran evidencias suficientes para afirmar que ocurra lo mismo en seres humanos, por lo que las clasifica dentro del grupo $2 \mathrm{~B}$, como posibles carcinógenos para los humanos ${ }^{52}$.

El National Institute of Occupatinal Safety and Health (NIOSH) señala que aparte del tamaño de las fibras, es necesario también tener en cuenta la dosis y la biopersistencia de las mismas, así como otros factores importantes como la composición química y la superficie de exposición de las fibras (NIOSH 2006) ${ }^{53}$.

Las FMA se incluyen en la lista de sustancias peligrosas en la Directiva 97/69/CE de la Comisión (1988), por la que se adapta al proceso técnico la Directiva 67/548/CEE, sobre clasificación, envasado y etiquetado de sustancias peligrosas que ha sido transpuesta en la Orden de 11 de septiembre de 1998 por la que se modifican los anexos I y VI del Reglamento sobre notificación de sustancias nuevas y clasificación, envasado y etiquetado de sustancias peligrosas, aprobado por Real Decreto 363/1995 de 10 de marzo.

A partir de la Directiva 97/69/CE, se establece un sistema de clasificación utilizando parámetros relacionando con la estructura, composición y con el peligro potencial cancerígeno de las fibras de vidrio a partir de lo que se definió como índice $K_{\mathrm{nb}}$, basado en el porcentaje de óxidos alcalinos y alcalinotérreos, distinguiendo dos categorías en función de sus características químico-físicas y toxicológicas. Cada una de estas dos categorías se subdividen a su vez en dos subcategorías teniendo en cuenta el diámetro de sus partículas. Las fibras con un diámetro mayor o igual a $6 \mu \mathrm{m}$ se consideraban irritantes y no así las de menor diámetro, independientemente de su composición química. Dado que algunos estudios experimentales sugirieron que la biopersistencia de las fibras 
inhaladas y depositadas en los pulmones podía influir en gran medida sobre la probabilidad de inducir efectos irreversibles en los pulmones o en la pleura, como fibrosis o tumores, la referida Directiva prevé en la Nota $Q$ del anexo I, la posibilidad de efectuar test basados en la medida en vivo sobre la biopersistencia a partir de la inhalación o instilación intratraqueal, por lo que además del índice $K_{\mathrm{nb}}$ y el diámetro de las partículas, se introduce el criterio de valores límite para distinguir entre fibras menos biopersistentes (-BP) y más biopersistentes (+BP) en base a los test efectuados ${ }^{54}$ (tabla III).

Tabla III. Relación entre el diámetro y composición de las FMA por el índice $\mathrm{K}_{\mathrm{nb}}$ en cuanto a la biopersistencia. Primera clasificación de las FMA (1998)

\begin{tabular}{|c|c|c|c|}
\hline & \multicolumn{2}{|c|}{$K_{n b}$ index $>18 \%$} & $K_{\mathrm{nb}}$ index $<18 \%$ \\
\hline & $-\mathbf{B P}$ & $+\mathbf{B P}$ & \multirow{3}{*}{$\begin{array}{l}\text { Fibras cerámicas } \\
\text { refractarias. }\end{array}$} \\
\hline Diámetro > $6 \mu \mathrm{m}$ & $\begin{array}{l}\text { Algunos tipos de } \\
\text { filamentos de vidrio. }\end{array}$ & $\begin{array}{l}\text { Algunos tipos de } \\
\text { filamentos de vidrio. }\end{array}$ & \\
\hline Diámetro < $6 \mu \mathrm{m}$ & $\begin{array}{l}\text { Algunos tipos de lanas } \\
\text { de vidrio, de escoria o } \\
\text { de roca. }\end{array}$ & $\begin{array}{l}\text { Algunos tipos de lanas } \\
\text { de vidrio, de escoria o } \\
\text { de roca; fibras para fines } \\
\text { especiales. }\end{array}$ & \\
\hline
\end{tabular}

Por otra parte, las fibras de vidrio han de ser consideradas también como productos químicos, y por tanto, dentro del marco de la normativa europea han de tenerse presentes también las medidas de prevención sobre productos químicos que se encuentra reguladas por la Directiva 98/24/CE del Consejo de 7 de abril de 1998, relativa a la protección de la salud y la seguridad de los trabajadores contra los riesgos relacionados con los agentes químicos durante el trabajo, y la Directiva 2007/30/CE del Parlamento Europeo y del Consejo, del 20 de junio de 2007, por la que se modifica la directiva 89/391/CEE del Consejo, sus directivas específicas y las Directivas 83/477/CEE, 91/383/CEE, 92/29/CEE y 94/33/CE del Consejo, a fin de simplificar y racionalizar los informes sobre su aplicación práctica.

En España El marco legislativo se establece a partir de la Constitución Española que encomienda a los poderes públicos velar por la seguridad e higiene en el trabajo. A partir de la transposición de la mencionada Directiva Europea 89/391/CEE se promulga la ley 31/1995, del 8 de noviembre, de Prevención de Riesgos Laborales (LPRL), que junto a la Ley 54/2003, del 12 de diciembre, que reforma del marco normativo de la prevención de riesgos laborales, establece, entre otros apartados, el derecho a la Protección y el Plan de Prevención de Riesgos laborales, la evaluación de riesgos, la planificación de la actividad preventiva y el riesgo grave e inminente para la Salud, mediante la prevención de los riesgos profesionales, la eliminación o disminución de los riesgos derivados del trabajo y la información, la consulta, la participación equilibrada y la formación de los trabajadores en materia preventiva ${ }^{55}$.

El Instituto Nacional de Seguridad e Higiene en el Trabajo (INSHT) de España incorpora los valores límites ambientales de exposiciones ocupacionales a diferentes agentes químicos, incluidas las fibras de amianto $^{56}$.

Los límites establecidos para la fibra de vidrio de filamento continuo y para las lanas minerales es de 1 fibra $/ \mathrm{cm}^{3}$, para las FCR y las fibras para usos especiales lo establece en 0,5 fibras $/ \mathrm{cm}^{3}$ en ambientes laborales.

\section{MEDIDAS DE PREVENCIÓN Y CONTROL}

La Organización Internacional del Trabajo (OIT) elaboró el repertorio sobre "Seguridad en la utilización de las lanas aislantes de fibra vítrea sintética (lana de vidrio, lana mineral de roca y lana mineral de escorias)", tras la aprobación por unanimidad de 
los expertos internacionales procedentes de distintos países de la UE, en la Reunión de expertos celebrada en Ginebra del 17 al 26 de enero de 2000, y que fue publicado por aprobación del Consejo de Administración de la OIT en su 277. ${ }^{a}$ Reunión celebrada en marzo de ese mismo año ${ }^{57}$.

En la elaboración del repertorio participaron veintidós expertos (siete designados por consultas con los gobiernos, siete tras la celebración de consultas con el Grupo de los Empleadores y ocho tras la celebración de consultas con el Grupo de los Trabajadores del Consejo de Administración) y en él se precisan las obligaciones y recomendaciones generales para fabricantes, proveedores, diseñadores, empleadores, trabajadores y autoridades competentes, por considerar que todos ellos desempeñan una función importante en el mantenimiento de la seguridad a lo largo de todo el proceso, desde la fabricación hasta la eliminación de desechos.

Aunque las recomendaciones prácticas del repertorio se refiere especialmente a las lanas aislantes de fibra vítrea sintética como la lana de vidrio, lana de roca y lana de escorias, tiene presente que otras fibras vítreas sintéticas como las fibras refractarias, de cerámica o no, y las fibras de vidrio especiales pueden resultar más peligrosas para la salud que las anteriores, por lo que muchas de sus disposiciones se encuentran orientadas hacia las buenas prácticas de prevención general y pueden ser aplicadas a la manipulación de fibras refractarias de cerámica u otras fibras de vidrio especiales, como complemento de las orientaciones que se encuentran en otros repertorios de recomendaciones prácticas como por ejemplo los repertorios de recomendaciones prácticas de la OIT Exposición profesional a substancias nocivas en suspensión en el aire (Ginebra, 1980) y a la Seguridad en la utilización del amianto (Ginebra, 1984).

El repertorio se encuentra concebido como un documento de referencia que incluye recomendaciones prácticas sobre formulación de estrategias, políticas y mecanismos relacionados con la seguridad en la utilización de lanas aislantes en el lugar de trabajo, aplicable a todas las formas de exposición de trabajadores a fibras y polvos de lanas aislantes de fibra vítrea sintética durante la fabricación, el transporte, almacenamiento, utilización, mantenimiento, extracción, traslado, reaprovechamiento y eliminación de las fibras de vidrio.

\section{Medidas de organización}

Sustentadas sobre la evaluación de los factores de peligrosidad en el trabajo y control de los riesgos laborales derivados de la utilización de lanas aislantes y otros productos químicos potencialmente peligrosos, teniendo en cuenta el siguiente orden jerárquico, la eliminación de riesgos mediante el uso de productos o tecnologías, el control de los factores de riesgo en su origen y la utilización de un equipo apropiado de protección individual. Para ello establece una serie de procedimientos basados en la evaluación de los peligros y de los riesgos, a adopción de medidas técnicas y de control, suministro de ropa y equipo de protección, dispensar una información adecuada sobre utilización de materiales, establecer programas de enseñanza y formación, asignación de responsabilidades tanto al personal de supervisión como a los trabajadores, establecimiento de mecanismos de consulta y el análisis del funcionamiento y la elaboración de planes de perfeccionamiento.

\section{Obligaciones generales}

\section{- Para los fabricantes:}

- Fomentar el perfeccionamiento incesante de los productos teniendo en cuenta composición capacidad de liberación de fibras y partículas de polvo, propiedades de biopersistencia y aditivos químicos.

- Elaboración de bases de datos detallando niveles de exposición en base a mediciones confirmadas. 
- Procurar que los productos puedan ser transportados, almacenados, utilizados y eliminados con una emisión mínima de partículas de polvo y de fibras.

- Proporcionar a los proveedores y a los usuarios, rótulos y datos apropiados sobre la seguridad de los materiales e información relativa a la salud de los materiales.

\section{- Para proveedores e importadores:}

- Velar por la transmisión de la información y las instrucciones a sus clientes.

- Ceñirse a lo estipulado por los fabricantes en materia de embalaje, almacenamiento, transporte, rotulación e información.

\section{- Usuarios, diseñadores y constructores:}

- Tener presente la elección sobre utilización de los materiales y la posibilidad de que se generen partículas de polvo y fibras durante las operaciones de instalación, utilización, mantenimiento y extracción.

- Mantenerse al corriente de la aparición de nuevos productos apropiados en lo que se refiere a la salud y la seguridad, según vaya progresando la tecnología de los materiales.

- Velar por cumplir los requisitos y documentos de especificación y licitación fijados por la autoridad competente.

- Contratación de empresas de material aislante que cumplan los requisitos de la autoridad competente.

\section{- Empresarios:}

- Tanto de empresas de extracción de materiales, fabricantes y usuarias deberían formular y aplicar normas de seguridad en el trabajo que se ajusten a los requisitos estipulados por la autoridad competente.

- Velar por que el diseño, la instalación, el funcionamiento y el mantenimiento de los procesos de producción y la gestión de los residuos en los lugares de producción generen un grado mínimo de partículas de polvo y de fibras en el ambiente de trabajo.

- Evaluar los peligros y los riesgos, informando a los trabajadores sobre esos peligros y riesgos, estableciendo un servicio apropiado de supervisión.

- Velar por que todos los trabajadores que intervengan en las operaciones de producción y manejen lanas aislantes reciban una formación e instrucciones adecuadas en relación con la seguridad en el trabajo.

- Elección, facilitación y conservación de los equipos de protección personal.

- Cerciorarse de que la exposición a polvos y partículas sea mínima y en todo caso inferiores a los límites mínimos establecidos.

- Aplicar unos procedimientos adecuados de mantenimiento del lugar de trabajo, y de extracción y eliminación de desechos, que reduzcan al mínimo la producción de partículas de polvo y de fibras.

- Mantener un proceso de consulta y cooperación con los trabajadores y sus representantes en lo que atañe a todos los aspectos de seguridad en la utilización de lanas aislantes.

\section{- Trabajadores:}

- Colaborar en la prevención, el control y la reducción al mínimo de la producción de partículas de polvo y fibras, con arreglo a sus atribuciones, teniendo en cuenta la información, las instrucciones y la formación que hayan recibido.

- Comunicar a su supervisor, y al empleador cuando sea preciso, las insuficiencias constatadas en materia de seguridad, así como todo incumplimiento de las normas correspondientes.

- Participar en los programas de formación y de instrucción organizados por el empleador o estipulados por la autoridad competente. 
- Aplicar las medidas de vigilancia y llevar adecuadamente el equipo de protección individual facilitado por el empleador.

\section{- Autoridad competente:}

- Elaborar o actualizar las disposiciones legales sobre protección de los trabajadores en colaboración con organizaciones de empresarios y trabajadores más representativos.

- Las disposiciones legales deberían englobar normas, recomendaciones prácticas y valores límites de exposición, según se requiera, así como los procedimientos adecuados de consulta y de difusión de información.

\section{CONCLUSIONES}

Los principales efectos sobre la salud relacionados con la exposición a FMA se producen sobre las vías respiratorias, al ser estas su principal mecanismo de entrada en el organismo, su capacidad patogénica se encuentran directamente relacionados con la mayor longitud de las fibras y su mayor biopersistencia. La concentración ambiental y la composición de las fibras también juegan un papel importante, aunque el riesgo de desarrollar alguna patología es prácticamente nulo con la aplicación de las medidas preventivas disponibles en la actualidad.

Existe cierta controversia en lo que respecta a los resultados de estudios experimentales en animales, mientras algunos autores piensan que estos modelos no son suficientemente sensibles y por tanto sus resultados son poco fiables cuando se extrapolan a los seres humanos. Otros por el contrario, consideran que estudios de este tipo, sustentados en la tecnología actual si son bien diseñados pueden evaluar determinados efectos potenciales carcinogénicos o fibrogénicos en el pulmón. En estudios experimentales, los tipos de fibra 475 glass y la E-glass parecen presentar efectos carcinogénicos o fibrogénicos en el pulmón.

La mayoría de estudios realizados en seres humanos no parece demostrar que exista relación entre exposición a diferentes fibras de vidrio y la aparición de patrones de fibrosis pulmonar o alteraciones seria pleurales, habiéndose descrito algunos casos aislados en circunstancias de especial exposición y la incidencia de estas patologías en poblaciones de trabajadores expuestos no han superado el $4 \%$.

Tampoco se encuentra una relación de la exposición a fibras de vidrio y la reducción de la capacidad pulmonar medida en FEV1 y FVC, y los hallazgos que muestran algún tipo de afectación en este sentido, parecen encontrase más relacionados con una asociación de la exposición al consumo de tabaco, al encontrarse principalmente afectados los fumadores o exfumadores.

Las FMA pueden desencadenar síntomas irritativos cuando entran en contacto con piel y mucosas, principalmente cuando el diámetro de las fibras es mayor de $4 \mu \mathrm{m}$, y en ocasiones, se han descrito alergias cutáneas relacionadas con el contacto con diferentes aditivos presentes en los compuestos de fibras de vidrio y en estudios realizados en poblaciones expuestas al edificio enfermo.

Los resultados de los principales estudios epidemiológicos realizados en poblaciones humanas, tanto en Europa como en Estados Unidos, han llevado a la IARC a concluir que no existen evidencias suficientes sobre la capacidad carcinogénica de las fibras de vidrio para los seres humanos, aunque parece que dos tipos de fibras, la fibra 475, la de tipo E y las FCR podrían comportarse como potencialmente carcinogénicos o precursores de fibrosis pulmonar en determinadas ocasiones, al menos a partir de resultados en estudios experimentales realizados en ratas y hamsters, sin que por el momento exista evidencia científica clara de que dichos efectos puedan encontrarse también en poblaciones humanas.

Estudios recientes analizando posibles efectos citotóxicos y genotóxicos, parecen indicar que las FMA de diámetro menor de $3 \mathrm{~lm}$ y longitud superior a los $5 \mathrm{~lm}$ pueden inducir alteraciones en las células A549 del epitelio alveolar de los seres humanos 
mediante un aumento de nitrógeno, estrés oxidativo y peroxidación de lípidos de la membrana, pero en la actualidad no existe evidencia suficiente que pueda sustentar esta hipótesis.

Aun así, faltan elementos suficientes que permitan alcanzar conclusiones sobre posibles efectos cancerígenos de las FMA en seres humanos a partir de resultados concluyentes basados en evidencias científicas, por lo que teniendo en cuenta determinados efectos observados en estudios realizados en animales, desde el punto de vista normativo de la UE se apoya en las recomendaciones de organismos internacionales como la International Agency for Research on Cancer (IARC), National Institute for Occupational Safety and Health (NIOSH), American Conference of Governmental Industrial Hygienists (ACGIH) y el Institut national de la recherche scientifique (INRS), considerando a las fibras de vidrio de filamentos continuos y las lanas de vidrio, roca y escoria dentro del grupo 3 como no clasificables respecto a su potencial efecto cancerígeno y las fibras cerámicas refractarias (FCR) dentro del grupo 2B como posibles cancerígenos para los seres humanos.

En conclusión, podemos considerar la fibra de vidrio como un material que presenta escasos riesgos para la salud en el medio laboral si se maneja bajo las medidas de control adecuadas o para la población general en sus aplicaciones habituales, constituyendo hoy día una de las mejores alternativas a la utilización de otros materiales que por el contrario han demostrado un comportamiento altamente peligroso para la salud, entre los que podemos citar al amianto entre otros productos de características similares.

\section{REFERENCIAS BIBLIOGRÁFICAS}

1. IARC, International Agency for Research onCancer Man-Made Vitreous Fibres, IARC Monographs on the Evaluation of Carcinogenic Risks to Humans IARC Press, Lyon, France, 2002, 181-240.

2. Foà V., Basilico S. Caratteristiche chimico-fisiche e tossicologia delle fibre minerali artificiali, Med Lav.1999,1;90,1:10-52.

3. Luoto, K., Holopainen, M., Karppinen, K., Perander, M. \& Savolainen, K. (1994a) Dissolution of man-made vitreous fibers in rat alveolar macrophage culture and Gamble's saline solution: Influence of different media and chemical composition of the fibers. Environ. Health Perspect., 102 (Suppl. 5):103-107.

4. Oberdörster, G. (2002) Toxicokinetics and effects of fibrous and nonfibrous particles. Inhal. Toxicol., 14:29-56.

5. Dörger, M., Münzing, S., Allmeling, A.-M., Messmer, K. \& Krombach, F. (2001) Differential responses of rat alveolar and peritoneal macrophages to man-made vitreous fibers in vitro. Environ. Res. Section A, 85:207-214.

6. Fubini B. Ipotesi sui meccanismi di azione biologica: ruolo della chimica di superficie negli effetti biologici delle fibre vetrose - Atti Seminario: Fibre Minerali Vetrose: la recente classificazione europea e le implicazioni del suo recepimento, Ist. Sup. San., 8-9 Ottobre 2001.

7. Bernstein DM. Synthetic vitreous fibers: a review toxicology, epidemiology and regulations. Crit Rev Toxicol. 2007; 37:839-86.

8. Le Bouffant L, Daniel H, Henin JP, Martin JC, Normand C, Tichoux G, et al. Experimental study on longterm effects of inhaled MMMF on the lungs of rats. Ann Occup Hyg. 1987;31:765-90.

9. Muhle H, Pott F, Bellmann B, Takenaka S, Ziem U. Inhalation and injection experiments in rats to test the carcinogenicity of MMMF. Ann Occup Hyg. 1987;31:755-64.

10. Kamstrup O, Ellehauge A, Collier CG, Davis JM. Carcinogenicity studies after intraperitoneal injection of two types of stone wool fibres in rats. Ann Occup Hyg. 2002;46:135-42.

11. Mast RW, Yu CP, Oberdörster G, McConnell EE, Utell MJ. A retrospective review of the carcinogenicity of refractory ceramic fiber in two chronic Fischer 344 rat inhalation studies: an assessment of the MTD and implications for risk assessment. Inhal Toxicol. 2000;12:1141-72.

12. Stanton MF, Layard M, Tegeris A, Miller E, May M, Morgan E, et al. Relation of particle dimension to carcinogenicity in amphibole asbestoses and other fibrous minerals. J Natl Cancer Inst. 1981;67:965-75.

13. Smith DM, Ortiz LW, Archuleta RF, Johnson NF. Long-term health effects in hamsters and rats exposed chronically to manmade vitreous fibers. Ann Occup Hyg. 1987; 31:731-54. 
14. Cullen RT, Searl A, Buchanan D, Davis JM, Miller BG, Jones AD. Pathogenicity of a special-purpose glass microfiber (E glass) relative to another glass microfiber and amosite asbestos. Inhal Toxicol. 2000;12:959-77.

15. Hesterberg TW, Axten C, McConnell EE, Oberdörster G, Everitt J, Miiller WC, et al. Chronic inhalation study of fiber glass and amosite asbestos in hamsters: twelve-month preliminary results. Environ Health Perspect. 1997;105(Suppl. 5):1223-9.

16. Cullen RT, Searl A, Buchanan D, Davis JM, Miller BG, Jones AD. Pathogenicity of a special-purpose glass microfiber (E glass) relative to another glass microfiber and amosite asbestos. Inhal Toxicol. 2000;12:959-77.

17. Hesterberg TW, Axten C, McConnell EE, Oberdörster G, Everitt J, Miiller WC, et al. Chronic inhalation study of fiber glass and amosite asbestos in hamsters: twelve-month preliminary results. Environ Health Perspect. 1997; 105(Suppl. 5):1223-9.

18. Hughes JM, Jones RN, Glindmeyer HW, Hammad YY, Weill H. Follow up study of workers exposed to man made mineral fibres. Br J Ind Med. 1993;50:658-67.

19. Takahashi T, Munakata M, Takekawa H, Homma Y, Kawakami Y. Pulmonary fibrosis in a carpenter with long-lasting exposure to fiberglass. Am J Ind Med. 1996; 30:596-600.

20. Guber A, Lerman S, Lerman Y, Ganor E, Trajber I, Edelstein E, et al. Pulmonary fibrosis in a patient with exposure to glass wool fibers. Am J Ind Med. 2006;49:1066-9.

21. Drent M, Bomans PH, Van Suylen RJ, Lamers RJ, Bast A, Wouters EF. Association of man-made mineral fibre exposure and sarcoid-like granulomas. Respir Med. 2000;94:815-20.

22. Sripaiboonkij P, Sripaiboonkij N, Phanprasit W, Jaakkola MS. Respiratory and skin health among glass microfiber production workers: a cross-sectional study. Environ Health.2009; 8:36.

23. Riboldi, L., Rivolta, G., Barducci, M., Errigo, G. \& Picchi, O. (1999) [Respiratory disease caused by MMVF fibres and yarn.] Med. Lav. 90:53-66 (in Italian).

24. Rossiter, C. E., Gilson, J. C., Sheers, G., Thomas, H. F., Trenthowan, W. N., Cherrie, J. W. \& Harrington, J. M. (1994) Refractory ceramic fiber production workers: Analysis of radiograph readings. Ann. occup. Hyg., 38:731-738.

25. Trethowan, W. N., Burge, P. S., Rossiter, C. E., Harrington, J. M. \& Calvert, I. A. (1995) Study of the repiratory health of employees in seven European plants that manufacture ceramic fibres. Occup. environ. Med., 52:97-104.

26. Lemasters, G., Lockey, J., Rice, C., McKay, R., Hansen, K., Lu, J., Levin, L. \& Gartside, P. (1994) Radiographic changes among workers manufacturing refractory ceramic fibre and products. Ann. occup. Hyg., 38 (Suppl. 1):745-751.

27. Lockey, J. E., Lemasters, G., Rice, C., Hansen, K., Levin, L., Shipley, R., Spitz, H. \& Wiot, J. (1996) Refractory ceramic fiber exposure and pleural plaques. Am.J. respir. crit. Care Med., 154, 1405-1410.

28. Lockey, J. E., LeMasters, G. K., Levin, L., Rice, C., Yiin, J., Reutman, S. \& Papes, D. M. (2002) A longitudinal study of chest radiographic changes of workers in the refractory ceramic fiber industry. Chest, 121:2044-2051.

29. Cowie, H. A., Wild, P., Beck, J., Auburtin, G., Piekarski, C., Massin, N., Cherrie, J. W., Hurley, J. F., Miller, B. G., Groat, S. \& Soutar, C. A. (2001) An epidemiological study of the respiratory health of workers in the European refractory ceramic fibre (RCF) industry. Occup. environ. Med., 58:800-810.

30. Lemasters, G. K., Lockey, J. E., Levin, L. S., McKay, R. T., Rice, C. H., Horvath, E. P., Papes, D. M., Lu, J. W. \& Feldman, D. J. (1998) An industry-wide pulmonary study of men and women manufacturing refractory ceramic fibers. Am. J. Epidemiol; 148:910-919.

31. Burge, P. S., Calvert, I. A., Trethowan, W. N. \& Harrington, J. M. (1995) Are the respiratory health effects found in manufacturers of ceramic fibres due to the dust rather than the exposure to fibres? Occup. environ. Med. 52:105-109.

32. McKay RT, LeMasters GK, Hilbert TJ, Levin LS, Tice CH, Borton EK, et al. A long term study of pulmonary function among US refractory ceramic fiber workers. Occup Environ Med. 2011; 68:89-95.

33. Lockey, J. E. \& Ross, C. S. (1994) Radon and man-made vitreous fibers. J. Allergy clin. Immunol. 94:310-317.

34. Thriene, B., Sobottka, A., Willer, H. \& Weidhase, J. (1996) Man-made mineral fibre boards in buildings - Health risks caused by quality deficiencies. Toxicol. Lett. 88:299-303.

35. Bergamaschi, A., Ripanucci, G., Sacco, A. \& De Lorenzo, G. (1997) [Indoor pollution from airborne glass fibers (MMMF) in biomedical research laboratories.] G. ital. med. Lav. Erg. 19:44-46 (in Italian).

36. Thestrup-Pedersen, K., Bach, B. \& Pedersen, R. (1990) Allergic investigation in patients with the sick building syndrome. Contact Derm.23:53-55.

37. Harry Shannon, Angus Muir, Ted Haine and Dave Verma. Mortality and cancer incidence in Ontario glass fiber workers. Program in Occupational Health and Environmental Medicine, McMaster University, 1200 Main Street, West Hamilton, Ontario M5G 2E9, Canada. Occupational Medicine. 11/2005; 55(7):528-34. 
38. Marsh, G. M., Youk, A. O., Stone, R. A., Buchanich, J. M., Gula, M. J., Smith, T. J. \& Quinn, M. M. (2001a) Historical cohort study of US man-made vitreous fiber production workers. I. 1992 fiberglass cohort follow-up: Initial findings. J. ocup. environ. Med. 43:741-756.

39. Marsh, G. M., Buchanich, J. M. \& Youk, A. O. (2001b) Historical cohort study of US man-madevitreous fiber production workers. VI. Respiratory system cancer standardized mortalityratios adjusted for the confounding effect of cigarette smoking. J. occup. environ. Med;43:802-808.

40. Stone RA, Youk AO, Marsh GM, Buchanich JM, McHenry MB, Smith TJ. Historical cohort study of US manmade vitreous fiber production workers. IV. Quantitative exposure response analysis of the nested case-control study of respiratory system cancer. J Occup Environ Med. 2001;43:779-92.

41. Gardner, M. J., Magnani, C., Pannett, B., Fletcher, A. C. \& Winter, P. D. (1988) Lung cancer among glass fibre production workers: A case-control study. Br. J. ind. Med;45:613-618.

42. Boffetta, P., Andersen, A., Hansen, J., Olsen, J. H., Plato, N., Teppo, L., Westerholm, P. \& Saracci, R. (1999) Cancer incidence among European man-made vitreous fibre production workers. Scand. J. Work environ. Health, 25, 222-226.

43. Simonato L, Fletcher AC, Cherrie JW, Andersen A, Bertazzi P, Charnay N, et al, The International Agency for Research on Cancer. Historical cohort study of MMMF production workers in seven European countries: extension of the follow-up. Ann Occup Hyg. 1987; 31:603-23.

44. Kjaerheim K, Boffetta P, Hansen J, Cherrie J, Chang-Claude J, Eilber U, et al. Lung cancer among rock and slag wool production workers. Epidemiology.2002;13:445-53.

45. Berrigan D. Respiratory cancer and exposure to man-made vitreous fibers: a systematic review. Am J Ind Med.2002;42:354-62.

46. Lipworth L, La Vecchia C, Bosetti C, McLaughlin JK. Occupational exposure to rock wool and glass wool and risk of cancers of the lung and the head and neck: a systematic review and meta-analysis. $\mathrm{J}$ Occup Environ Med.2009;51:1075-87.

47. Roser Costa y Ramon Orriols. Fibras minerales artificiales y aparato respiratorio. Arch Bronconeumol.2012;48(12):460-468

48. Lemasters, G., Lockey, J., Levin, L., Yiin, J., Reutman, S., Papes, D. \& Rice, C. (2001) A longitudinal study of chest radiographic changes and mortality of workers in the refractory ceramic fiber industry (Abstract at the 2001 Congress of Epidemiology) (Abstract No. 986). Am. J. Epidemiol; 153 (Suppl. 264).

49. Walker, A. M., Maxim, L. D. \& Utell, M. (2002) Risk analysis for mortality from respiratory tumors in a cohort of refractory ceramic fiber workers. Regul. Toxicol. Pharmacol;35:95-104.

50. IARC (1988) IARC Monographs on the Evaluation of Carcinogenic Risk to Humans, Vol. 43, Man-made Mineral Fibres and Radon, Lyon, IARCPress: 33-171.

51. Cavallo D., Campopiano A., Cardinali G., Casciardo S., De Simone P., Kovacs D., PerniconiB., Spagnoli G., Ursini C. L., Fanizza C. Cytotoxic and oxidative effects induced by man-made vitreous fibers (MMVFs) in a human mesothelial cell line. Toxicology, (2004) 201, 1-3, 219-29.

52. International Agency for Research on Cancer (IARC). IARC Monographs on the Evaluation of Carcinogenic Risks to Humans. Man-Made Vitreous Fibres, 81. Lyon, France: IARC; 2002. [consultado julio 2015].

53. NIOSH, National Institute of Occupational Safety and Health Occupational Expousure to Refractory Ceramic Fiers, Criteria for a Recommended Standard. Departement of Health and Human services, Centers for Diseases Control and Prevention, USA. 2006: 123.

54. Direttiva 97/69/CE Ventitreesimo adeguamneto alprogresso tecnico della Direttiva 67/548/CEE del Consiglio concerenente il ravvicinamento delle disposizioni regolamentari ed amministrative relative alla classificazione, imballaggio, e all'etichettatura delle sostanze pericolose in recepimento della Direttiva 97/69/CE, Gazzetta Ufficiale U. E. L. 343/1997. 1997.

55. Guía Tecnica para la evaluación y prevención de riesgos relacionados con los agentes químicos en los lugares de trabajo. Instituto Nacional de Seguridad e Higiene en el Trabajo (INSHT). Ed. Servicios Gráficos Kenaf, SL. 2003. Madrid. ISBN: 978-84-7425-810-325.

56. Límites de exposición profesional para agentes químicos. Instituto Nacional de Seguridad e Higiene. Ministerio de Trabajo e Inmigración. 2011.

http://www.insht.es/InshtWeb/Contenidos/Documentacion/TextosOnline/ValoresLimite/limites2011/ Limites2011web.pdf.[consultado julio 2015].

57. Seguridad en la utilización de las lanas aislantes de fibra vítrea sintética (lana de vidrio, lana mineral de roca y lana mineral de escorias). Repertorio de recomendaciones prácticas de la OIT Ginebra, Oficina Internacional del Trabajo, 2001. (Versión en inglés: ISBN 92-2-211629-1, Ginebra, 2001). (Versión en francés: ISBN 92-2-311629-5).

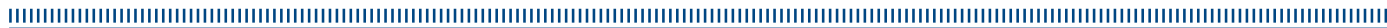

